\title{
Strength-training and biological rhythm of male sex hormone among judoists
}

\begin{abstract}
Testosterone is a steroid hormone that is secreted by the testes with a diurnal rhythm and has a strong anti-catabolic (anabolic) effect on muscles. There is a strong relationship $(r>0.9)$ between concentrations of testosterone in the saliva and blood. The main purpose of the current study is to investigate the effect of strength-training on levels of salivary testosterone in male judoists. In a cross-sectional investigation, a population of 18 fit young male judoists (aged $17.0 \pm 1.2$ year, body mass $72 \pm 3 \mathrm{~kg}$, height $175 \pm 3 \mathrm{~cm}$, means \pm SD), with at least 1.5 years of experience in judo classes was examined in Isfahan, Iran, in December, 2012. The period of testing consisted of two days of "rest" and two days of "exercise". Subjects were randomly divided into two conditions that performed either the "rest" or "exercise" days during the first week, with the opposite type of day in the second week. The training regimen consisted of three repetitions of nine tasks, with 1 min of rest between each of the three sets, performed on alternate days for 8 weeks. Unstimulated saliva was collected $(1-2 \mathrm{ml})$ every $2 \mathrm{~h}$ from 06:00 till 22:00 h. ANOVA with repeated measures was used to assess differences between the rest and exercise days. Strength-training sessions caused a significant decrease in testosterone levels immediately after exercise $(p<0.001)$, but there was no significant difference between the daily profiles of testosterone during the rest or exercise days $(p>0.05)$. It is concluded that strength-training does not significantly affect the normal biological rhythm of salivary testosterone during the waking period in male judoists.
\end{abstract}

Keyword: Saliva; Male sexual hormone; Strength-training; Judoists 